\title{
Preliminary project design for insect production: part 4 - facility considerations
}

\author{
R. Kok \\ Bioresource Engineering, Macdonald Campus of McGill University, 21,111 Lakeshore Rd, Ste-Anne-de-Bellevue, QC H9X \\ 3V9, Canada; robert.kok@mcgill.ca
}

Received: 14 December 2020 / Accepted: 6 January 2021

(c) 2021 Wageningen Academic Publishers

OPEN ACCESS (C) (1) (2) (2)

\section{TECHNICAL REPORT}

\begin{abstract}
At the end of the preliminary project design (PPD) phase an aspiring entopreneur should have a clear idea of the scope and scale of the project being proposed. Hence, during PPD a number of aspects of the facilities must be considered. These are here dealt with in terms of basic questions that should first be answered about the project as a whole; project location issues; to what degree the facility is to be integrated or segregated into different units; what functionality is to be housed within the various building envelopes; and how safety and hygiene concerns can be addressed. As well, three ancillary issues are discussed that may affect facility design, construction and operation: the development of new production organisms that can grow on low-cost feeds; the possibility of disease evolution; and the matter of animal welfare.
\end{abstract}

Keywords: entotechnology, design, safety, hygiene

\section{Introduction}

In Parts 1, 2 and 3 of this set of papers a number of aspects of preliminary project design (PPD) for the mass production of insects were addressed including the calculation of some basic process heat and mass balances (Kok, 2021a), consideration of organism/feed kinetics and the use of modelling and simulation for process evaluation and design (Kok, 2021b), as well as the pros and cons of a number of process types and operating modes (Kok, 2021c). All this to help the aspiring entopreneur crystallise their project concept and arrive at a preliminary design (see Figure 1 of Kok, 2021a). For practical reasons the discussion has been chiefly oriented to the rearing of black soldier fly larvae (BSF, Hermetia illucens) and mealworms (Tenebrio molitor and relatives). The same holds true for this paper. Much of the reasoning and methods discussed are, however, also applicable to dealing with the eggs, pupae and adults of these two organisms as well as the production of other insects and related Arthropoda such as spiders and scorpions.

Before starting to consider actual facility requirements the entopreneur should have a clear idea of what exactly they want to do and accomplish in their project. Thus, as part of concept crystallisation and PPD they should have considered and formulated answers to a number of very basic questions about the project. Such questions would also be asked immediately by anyone interested in investing in the project but first wanting to scrutinise its viability in a preliminary manner. The answers to these questions will influence the facility arrangements very strongly and are therefore reviewed here first.

\section{Basic questions}

The first basic question concerns the nature of the project and the industrial sphere which it will touch most. Thus, what is the overall intent and purpose? At the moment there are three main spheres in entotechnology, as well as a host of minor ones: the production of food for human consumption; the production of feed for animal consumption, including pet food; and the conversion of a negative-value waste or a low-value by-product into an industrial material that will not enter the food or feed chain. A current example of insect-based human food is mealworm powder while many animal feeds and pet foods are now derived from BSF larvae, sometimes in fat-reduced form. BSF is also used to a limited extent for negative value reduction of substrates, e.g. for manure management. The production of insect-based fuels, chitin, enzymes and other bio-materials, 
although developing, is still in its infancy. Because they may be based on the same or similar organisms, the kinetics and the process types employed in these different applications can be quite similar. However, the hygienic and operating requirements for the facilities in which these processes would be housed may, at the same time, be very different. Thus, many of the organisational and physical aspects of a project will depend directly and strongly on its overall purpose. Some of these aspects will also depend to some degree on where the project will be located.

The second main question, obviously closely connected to the first, addresses the organism/feed combination that is chosen for the project, together with what the main project inputs and outputs will be. Is the entopreneur planning to rear mealworms on a mix of whole wheat flour, soybean and some additives to produce mealworm powder suitable for direct human consumption? And will they perhaps process (dry, grind, clean, etc.) it locally and package it in-plant in $100 \mathrm{~g}$ nitrogen-flushed, composite-walled, self-sealing baggies for distribution via the organic food division of large grocery retailers? Or perhaps the objective is to rear BSF larvae on-farm on a suitably fortified by-product that qualifies for inclusion in the food chain. In this case the eggs might be acquired on a daily basis from an external supplier and the larvae fed live to chickens well before they reach pupation. Etc. The possibility space for any of these endeavours is very extensive and can be investigated by means of simulation before any major commitment is made to a specific project (Kok, 2021b).

Once an overall direction has been chosen and an organism/ feed combination selected, the third major question to address is which activities will be carried out locally. For instance, a complete process for BSF production will include feed preparation, adult maintenance, egg incubation, larval rearing and pupal incubation so that the entire reproductive cycle will be maintained locally, with the excess larvae being the main process output. As well, the larvae may even be processed into oil and high-protein feed at the same location so that they will be the main outputs. This is in sharp contrast to a plant receiving eggs and a pre-mixed feed on a daily basis from external suppliers and shipping out fully grown larvae, perhaps frozen, for processing elsewhere.

Another major question is at what scale to operate. At the very low end an entopreneur may wish to convert mixed by-products from a market-garden operation into insect mass to feed to fish, chickens or pigs. In many such cases, due to locality, restrictions on food chain entry don't apply, very simple processes and operating methods are employed, and a production capacity of 10 $\mathrm{kg} /$ day is entirely satisfactory. Once the production volume increases to $100 \mathrm{~kg} /$ day the entopreneur's classification shifts from 'very-low end' to 'small producer' and they will probably employ a more advanced process type and also start to rely on some automatic control (see Kok, 2021c). As production volume shifts further to 'intermediate', it becomes more or less imperative to utilise an industrial approach so that increasingly sophisticated process types and operating methods must be employed. All major plants currently being brought online fall into that category with production capacities in the range of $1000-10,000 \mathrm{~kg} /$ day, their processes based on multiplexed arrangements, as collections and as manifolds, usually both (Kok, 2021c). In addition, their control systems almost invariably rely on some artificially intelligent components. With this output capacity most are, essentially, industrial-scale demonstration plants that will serve as proof-of-concept for much larger scale developments.

A truly exciting prospect for entopreneurs (and especially for engineers working in this field!) is the creation of 'worldscale' plants with production capacities in the range of a million $\mathrm{kg} /$ day. If one only thinks about the protein requirements of the human population the following simple (approximate!) calculation illustrates the feasibility, and even the desirability, of building at this scale: for a human population of 8 billion individuals of average weight 40 $\mathrm{kg}$, the total daily protein requirement will be 256 million $\mathrm{kg} /$ day $(0.8 \mathrm{~g} / \mathrm{kg}$.day). If $10 \%$ of that demand is to be met with insect-derived material and the protein content of an insect is $20 \%$ (e.g. mealworms on a wet basis), then the total demand for insect mass (wet basis) to supply this much protein to the human population will be 128 million $\mathrm{kg} /$ day. Now, considering that the demand from the animal feed sector will likely be much larger than this it would seem that, on the world stage, there is definitely room for at least a hundred plants of this scale. After preliminary processing, a plant with a production capacity of one million $\mathrm{kg} /$ day live larva would have as major outputs about $200,000 \mathrm{~kg} /$ day of dry protein powder and 150,000 kg/day of fat (based on approximate mealworm composition). This is the equivalent of a loaded transport truck (20 tonnes net) leaving the plant once every hour during a two-shift work day. If a hundred plants of this capacity were built, together they would produce 36.5 million tonnes/year of wet material. Compared to other animal-derived food sources that would not be an overwhelming contribution but, because it might be additional to these other sources rather than a replacement, it could prove to be significant in terms of supplying high-quality protein to low-income groups and thus offset sub-optimal protein values in people's diets. In comparison to the number presented above for the 100 world-scale plants (36.5 million tonnes/year) some world production values are, in millions of tonnes/year: meat 350 (dressed carcass weight, including poultry); milk: 850; eggs: 80; both aquacultured and captured sea foods: each well over 100 (Ritchie and Roser, 2017, 2019). It is likely that industrial-type facilities will need to be built to realise production at the million $\mathrm{kg} /$ day scale if the following three 
objectives are to be met simultaneously: food safety, food quality, and low cost. In order to have a major impact on the global protein supply scene, the cost of insect-derived protein should ultimately be brought well below that of any of the other sources.

The fifth major question facing an aspiring entopreneur is what process type to employ in the project. Within this consideration are folded related questions about the heart of any process, the reactor, as well as the operating method and the control approach. Of course, the scale of the project will play a major role in any decision made about the process type and all related aspects. Will the process be based on plug-flow or a continuous stirred tank reactor approach? Will it be batch, semi-continuous or continuous? Will it be a simple process or multiplexed? If the latter, collection or manifold-based, or both? Will the reactor(s) be active or passive (see Kok, 2021b)? Again, answers to these questions will be closely intertwined with the aspects discussed above. And, evidently, they will also partly depend on the entopreneur's vision of the project and their preferences.

The final major question addressed here concerns the knowledge on which project decisions may be based. As discussed by Kok (2021b), such decisions may be arrived at through mentation pathways that are either accessible and inspectable, purely intuitive and as such not inspectable or, as is more usual, a combination of these two possibilities. The former type of mentation can be supported with a modelling and simulation approach while both types can be subject to a certain amount of emotional influence, e.g. due to an entopreneur fulfilling their 'dream'. Regardless of which decision-making pathway is mainly employed, specific and detailed knowledge of the kinetics of the proposed organism/feed combination is essential for the PPD exercise to yield useful results (Kok, 2021b). In addition, detailed knowledge of the functioning of the proposed process type, reactor configuration, operating methods and control approach are also necessary. Although in this paper the subject is not really dealt with beyond being mentioned, a good grasp of the micro-economics of the situation is obviously also required. Items that need to be dealt with in detail are: feed supply and cost and what impact the project might have on these; potential product demand; land and construction costs in the proposed locale; presence of transport infrastructure; labour availability and cost; environmental and safety legislation.

To sum up: facility considerations and decisions about facility arrangements will depend on a host of features of a proposed project. An entopreneur can decide to start a project and build a facility for many different reasons. Depending on the product and the situation, it is possible to build at a wide range of scales, use a variety of process types and reactor configurations, then operate and control the process in different ways. Concept development should be knowledge-based while it should be recognised that knowledge will need to be augmented as the concept shifts during development. Kok (2021a) has referred to these two aspects as the 'twin components of an iterative knowledge engine'. Project concept development can be supported, facilitated and enhanced with simulation based on a set of interactive models that are representative of the various concept components, e.g. the feed, the organism, the reactor, the process operation, the control system, and even some supply and demand aspects. In essence, the PPD exercise serves to explore the possibility space for a project while all decisions remain provisional and malleable until its conclusion. Thus, it is an iterative procedure during which any and all aspects of the project can initially be anchored but then re-considered as new opportunities come to light. Although most PPD work will concern addressing the basic questions outlined above, a number of ancillary but very practical issues will also arise and these are referred to here as 'facility considerations. These issues will arise regardless of what industrial sector the project fits in, the organism/ feed combination, the scale, the process type, etc. A number of these issues were also mentioned by Kok (2017).

\section{Consideration 1: location issues}

Once an overall project plan has been assembled one of the first question that arises is where it should be located. What factors should be taken into consideration in choosing the plant site? For small projects the answer is often obvious: it will be at or very near the residence of the entopreneur, especially if the process is to be manually operated and supervised. Although detailed data are not available on numbers, from the popular literature and media it is evident there are now thousands of such small production facilities around the world, on all continents. For slightly larger projects the answer requires some more consideration. For instance, how much land should be acquired initially for the project to be established and how much room should be allocated for subsequent expansion? This will often depend on the cost of land but also on the cost of moving a facility to a new location once it proves successful. In the long run it might be less costly to initially acquire more land so that later on it will be easier to expand production by multiplexing, i.e. adding a second and third identical reactor right beside a first one. Thus, the choice of location may be influenced strongly by the price and availability of land.

The second issue is reliable access to adequate feed at a low, stable cost. This is highly location sensitive and becomes more so as the scale of the project increases. For instance, for a world-scale plant (output 1 million $\mathrm{kg}$ /day live larvae, using the values of Liu et al. (2020) for mealworms which are: $64 \%$ water, $18 \%$ protein, $14 \%$ lipid, $3 \%$ carbohydrate and $1 \%$ ash) the input stream would need to be roughly(!) 1 million kg/day of dry material (starch or cellulose, taking into account undigestible materials, undigested feed, losses, 
etc.) or 365,000 tonnes/year. Taking a 'normal' yield of $0.7 \mathrm{~kg} / \mathrm{m}^{2}$ year dry mass for kernel corn as the basis for the calculation, supplying this amount of feed will take 52,000 ha of productive farm land or about 100,000 ha of land in total (accounting for roads, non-productive land, other uses, housing, etc.) to supply such a plant. This is equivalent to $1000 \mathrm{~km}^{2}$. Thus, almost all available farm land in a circle of $18 \mathrm{~km}$ radius must now be dedicated to growing feed which must then be transported to the plant. If the supply density is lowered, i.e. if other crops are grown in the area as well as feed for the plant, the supply radius must be enlarged and transportation costs will increase. Although the calculations presented above are very approximate (!), they do provide some insight into how overall production of feed and the transportation infrastructure should be planned for a region if one is to install a major conversion facility. This holds for whatever the planned feed is. For instance, if the plan is to rear a cellulolytic organism on forestry waste on an industrial scale, the location should probably be chosen accordingly so that a sustainable supply (at a constant cost) and transport of that feed can be ensured in the longer term.

A third issue that is directly related to location is the air supply to the plant and, concomitantly, the exhaust. In many ways a rearing facility is no different from any other type of farm in which animals are confined while converting feed into more valuable materials. To do this, they require fresh air of good quality. Although, to facilitate the supply of feed, it may seem attractive to locate a plant in an agricultural area one danger of doing so is that there may accidental, airborne releases of insecticides that will enter the main air intake and then be distributed by the heating, ventilation and air conditioning system throughout the plant before ever being noticed. The way to offset this possibility, as well as to guard against air-borne organisms and other contaminants, is to thoroughly filter and wash all the intake air. Evidently, this comes at a cost! There is a similar problem with the exhaust from the plant because it will have an odour as well as a fairly high carbon dioxide content. And it may also contain small particles such as dust from the feed, insect setae, fungal spores, etc. The smell of the exhaust can be reduced by washing and the particles can be removed with filtering but there is no practical way to reduce the carbon dioxide content so that one must rely on adequate downwind dilution for this. These issues also limit the location for a plant, certainly making it very difficult to locate one in an urban setting. Concerns about exhaust from livestock facilities are not new and have been addressed in detail by many authors, e.g. Ubeda et al. (2013). Problems associated with the air supply and the exhaust will increase in direct proportion to the scale of the plant and, except for very small scale operations, must not be ignored, at the peril of the entopreneur. They should be dealt with during the PPD phase of the project rather than after the neighbours have started to complain to health authorities about odour overload or respiratory problems. At the same time, it should be investigated how compatible insect production is with the neighbourhood. For instance, what are the neighbours exhausting that could possibly end up in the air intake of the facility and what other sources of environmental contamination are nearby? Examples of such are large roads, railways, chemical plants, etc. The placement of the facility's main air intake and the relative placements of the air intake and the exhaust are discussed further in the section on facility segregation and integration below. Kok (2017) has also discussed some aspects of these issues.

The last issue mentioned here that is specifically locationrelated concerns the possibility of a sudden and dramatic failure of the plant envelope due to human error, natural disaster, terrorism, etc. Such a failure could lead to the instantaneous release of millions or even billions of insects which could have serious safety consequences. A large cloud of BSF adults, although not actually dangerous in any particular way, could blind drivers on a nearby highway and several million crickets moving together towards a neighbour's property might very well cause panic. There are anecdotes in circulation about a cockroach farm being accidentally demolished with some quite unpleasant consequences. In short, most neighbours would not appreciate a host of flying, hopping or crawling insects advancing upon them and this means that the location for the plant should be selected to minimise the impact of any major system failure. The entopreneur should therefore ensure that the property is large enough to allow for a safety and nuisance perimeter. This will also minimise the impact of incidentally released organisms which can be a routine bother to neighbours. For larger facilities an industrial zone as close as possible to the main source of feed is probably optimal.

A number of other project aspects are also somewhat, but not entirely, location-dependent. These are mostly related to the main liquid and solids inputs and outputs to and from the plant. The main liquid input to a plant will be water which, depending on the location, may be obtained from a central source or will have to be pumped, filtered, and purified locally. Kok (2017) discussed the water supply issue and how different water qualities are required for operation of the process, personnel, cleaning, etc. Standard technology is available to address any problems related to water supply but usually the lowest cost approach is to source from a central municipal supply, if available. A less trivial issue is the disposal of liquid wastes such as large volumes of heavily contaminated wash water with a high biological oxygen demand load. Again, for a larger facility, it is probably easiest and best to reject liquid wastes to a sewer system for central processing. If that is not available the plant will need to have its own treatment equipment - not an insignificant matter! Thus, whereas a small capacity plant could be located in a setting serviced by normal municipal 
infrastructure, for a plant of any significant capacity it will be easiest to locate it in a serviced industrial zone where large volume water demand and liquid waste disposal are normal requirements. If that is not possible, a water source will be needed nearby and adequate space on the property will need to be allocated for liquid waste treatment. Again, odour problems must to be taken into account.

Much of the same reasoning holds for the supply and management of solids. The main solids input will be feed and that will probably arrive at the plant by truck. Thus, adequate road infrastructure is needed to accommodate the traffic. And it is likely that high-value outputs like protein powder and lipids will leave the plant by truck also, using the same roads. For pretty well all organisms, however, a substantial amount of solids remains after the target material has been harvested (see Kok, 2021a). This material will be a mixture of non-digested feed, castings, frass, dead insects, etc. and can vary in consistency from a fairly dry granular mix to a thick sludge. It may be possible to separate a fraction of this and process it into other marketable products (e.g. insect frass) but a substantial amount of solids will remain to be disposed of. If the plant is located in an agricultural area and adequate space is available it may be possible to compost this material locally and then use it as a soil conditioner and fertiliser. If the plant is located in an urban setting or an industrial park it will, however, have to be removed by truck for offsite treatment, stabilisation and disposal. It should be noted that, whereas in many instances the leftover solids from insect culture are seen as a valuable resource with a lot of potential it is, at the same time, a heavily contaminated material whose bacterial load is uncertain and that may contain many other organisms of public health interest. It should, therefore, be treated with considerable caution while how it can be dealt with will depend partly on the location.

\section{Consideration 2: degree of integration and segregation in the facility}

Although the emphasis throughout the discussion of PPD has so far been on the rearing of the target organism, from the above it is evident that a considerable number of other aspects of a project must also be taken into consideration in making final or semi-final decisions about a project. Thus, factors such as the infrastructure that is available and the risk of establishing a plant at a proposed location will also play an important role. Once several primary candidate locations have been identified and it is clear what services will have to be provided locally it is possible to assess the required composition of the facility at each location and evaluate the risks and advantages. Obviously, all this will vary tremendously according to the scale, the process, the locale, etc. For example, a proposed project might be about a facility of intermediate scale (e.g. 10,000 kg/day), meant to digest mainly urban organic waste by means of
BSF larvae, with access to a full complement of industrial infrastructure, receiving eggs daily from a specialised supplier, and able to send its output (larvae) to an external processor for chemical oil and protein extraction while its waste solids can be shipped to an external composting facility. In another scenario the plan may be to set up a relatively small plant in a non-industrialised area to convert a low-cost starch source into insect protein and fat so as to improve the quality of the local diet. In this case a number of infrastructure-related units may need to be included in the facility, e.g. a reliable water supply while, at the same time, some other factors will probably be less significant. In such situations issues like feed supply security, odour emission, mass releases of organisms, etc. are often not major items on the PPD agenda. Of course, quite on the contrary, if the project plan is to establish a world-scale plant they must be, simply because the implementation of the plan can have a major local effect on these factors and even a national or international impact. In all cases the questions to be asked during the PPD stage are: what units will need to be incorporated in the facility and what will be the relationship between them? And, to what degree should the facility be integrated and/or segregated?

Basically, 'integration and segregation' refers to which activities are to be carried out under the same or different roofs, within the same or in different envelopes. There are some major advantages to having all units comprising a facility within the same envelope, mainly related to convenience; ease of operation; cost of construction, maintaining and operating the plant; utilisation and management of personnel; communication, etc. But there are also some major disadvantages and it is a matter of deciding which factors outweigh the others. Thus, in any facility in which animals are raised in a high density the danger of disease striking and propagating very rapidly is ever present, some species being more resistant to this than others (see Eilenberg et al., 2015; Joosten et al., 2020). As well, the likelihood of the end product becoming contaminated with feed or waste is much larger if, e.g. larval processing takes place in the same building as feed preparation and larval rearing. Other activities, like waste treatment or standby-power generation, are entirely incompatible with processing. Thus, how the various units are to be segregated will depend, firstly, on what functionality is to be integrated in the facility and, secondly, on how serious the problems that will accompany integration are judged to be. Kok (2017) has addressed some of these issues, pointing out that for a 'complete' facility strain breeding and testing should probably be carried out in an entirely separate, auxiliary unit and that it would be wise to do the same for strain maintenance and inoculum preparation (i.e. eggs). This is in direct imitation of many other biotechnology industries such as brewing and enzyme production. That same approach is also used in the poultry industry for larger-scale facilities 
and even pork producers are moving in that direction. If it is necessary to treat them locally, both solid and liquid wastes should definitely be dealt with in auxiliary units that are far enough removed from the rearing and processing units (and downwind of them) so as to minimise the chance of contaminating the rest of the facility. Although it may be more difficult to arrange, ideally, exhaust gas treatment and cleaning should also be done a good distance removed from the main production area and the exhaust released so as to prevent 'short-circuiting' of the air flow, i.e. the exhaust gas should never be able to enter the intake. The air inlet should therefore always be put upwind from the exhaust, in accordance with the local, prevailing wind pattern. Another way to reduce short-circuiting is to put the air intake and exhaust at different heights. A location with fairly steady winds and a tall chimney for the plant exhaust are therefore a good idea. Even though standby power generation is generally not thought of as a major feature of a plant, for a rearing facility it is essential and sufficient generating capacity should be installed for the plant to keep operating throughout a fairly prolonged power interruption. When a full-sized, industrial genset (often diesel-powered) is running it generates a large amount of exhaust gas of variable quality and it is best to also vent that exhaust through a chimney so that it won't reach the inlet of the plant. It can, therefore, be situated near the exhaust treatment unit and vented through the chimney. Depending on how a plant is multiplexed and what its production scale is, it may also be desirable to clean the intake air in a separate, auxiliary unit. This allows for discrete, qualitycontrolled airflows into different sections of the plant. Obviously, by segregating the units the plant will have a larger footprint than when it is fully integrated. Also, more supply and transportation infrastructure is needed to provide services to the various units and to move materials between them. This will, inevitably, increase the cost of constructing the plant.

A sample layout for a production facility incorporating some of the aspects discussed is presented in Figure 1. It is not to scale (!) and only the main material flows are shown. In this instance the facility is quite segregated with primary inputs (feed and eggs) being received at one loading dock and the primary outputs (protein powder and oil) being shipped out via another loading dock. Water is obtained from a well and treated locally. The intake air is cleaned and conditioned in a separate unit before different streams are sent to rearing and processing. A third, separate air stream is allocated to the personnel unit which is kept far away from any of the production units. This is done to ensure worker safety as well as to reduce the danger of contaminating the process. Exhaust from all sources is combined for cleanup and is then disposed of via a chimney. Liquid wastes are treated locally while solid wastes are removed for off-site composting. Larval rearing and processing are done in separate units with trays moving between them in a cyclical pattern. In this layout the main air intake and the personnel unit both face the prevailing winds and are upwind from all the other units. While working on the PPD stage of a project an entopreneur would probably generate many such diagrams while considering the possibilities and probabilities together with the pros and cons of each arrangement.

The question of segregation vs integration does not only apply to the facility as a whole; it is equally applicable to the organisation of the rearing and processing units where actual production activities take place. Thus, depending somewhat on the production scale and how the process is multiplexed it may be highly desirable to keep groups of organisms strictly isolated from one another. In Figure 1 the rearing sub-process illustrated is 'manifolded, immobile, fed-batch, and collection-based' (see Kok, 2021c), meaning that feed and eggs are initially loaded onto trays together and that this mixture stays on the same tray during the entire larval residence in the reactor, that an entire collection of trays is prepared almost at the same time so that their age distributions will be similar, that feed is added to each tray during its residence in the reactor, and that this procedure is repeated at regular intervals in an overlapping manner so that a manifolded multiplex is created. This will result in regular outputs so that the processing unit will have a high utilisation factor. In this case the main rearing unit contains fourteen compartments corresponding, for example, to fourteen days of egg/larval residence time. The question will be to what degree these rearing compartments should be kept isolated from one another. For smaller facilities this may very well be impractical but for larger ones it will probably be prudent to limit contact between them. Thus, each compartment should be supplied separately with air, water and feed. Low-level controls should be localised while reporting regularly to a centralised, high-level control and management system. This will augment system stability and resilience while reducing its vulnerability to infection, power fluctuations, physical breakdowns, etc. Movement of personnel through the rearing facility, and particularly through the different sections of the rearing manifold, should be severely restricted to reduce the incidence of disease transmission. As the magnitude of mass culture of organisms such as BSF, mealworms and crickets increases rather dramatically, the potential for serious economic damage due to infection also rises. This has certainly occurred in other, related industries (see Jones et al., 2018; Pitts and Whitnall, 2019) and the entotechnological sector is no exception to this danger.

In some ways keeping the various units isolated from one another will increase the complexity of the facility although it can also make it simpler to expand its capacity. In the layout in Figure 1 there is no space allocated for expansion and once this organisational arrangement has been agreed upon in a general way the entopreneur may decide to modify it to allow for future increase in capacity. The easiest way 


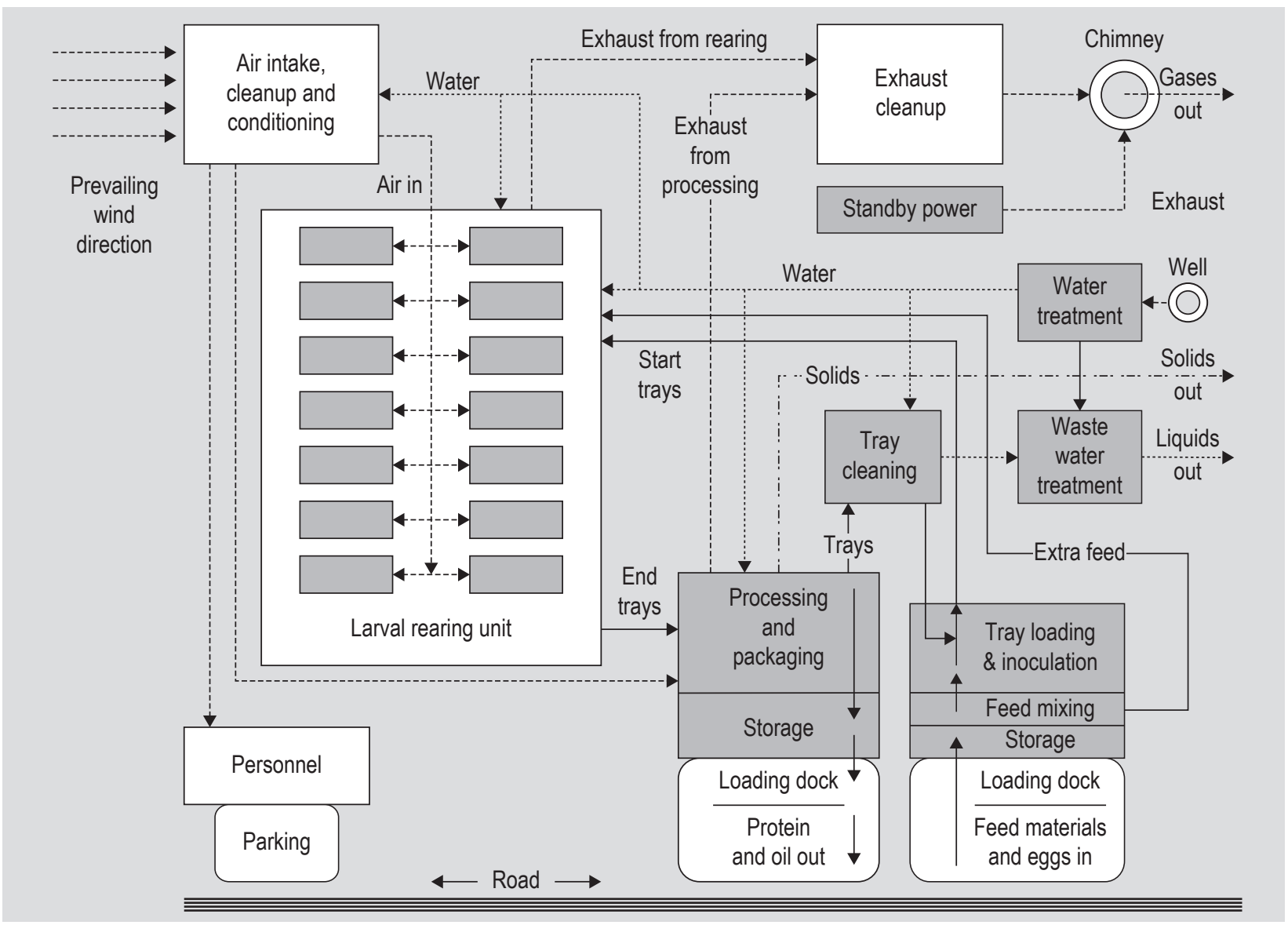

Figure 1. A sample layout for an egg-to-larvae production facility.

to do that is to make sure the infrastructural units will be able to handle a larger load, to build the processing unit somewhat larger than needed at the start and to leave space on the property for extra rearing units. The great advantage of a 'plug-in' modular approach is that capacity can be increased relatively easily by multiplexing. For instance, the capacity of the facility illustrated in Figure 1 can be doubled simply by adding another rearing unit, as long as the air cleaning, feed mixing, tray preparation units, etc. can handle the increased demand.

\section{Consideration 3: within the envelopes}

In the above example all the major units comprising a facility are kept physically separate and at an adequate distance from one another. This approach is probably applicable to larger projects but not necessarily practical or affordable for smaller or intermediate-sized ones. Consequently, the question that often arises is which operations can be combined under the same roof, within one envelope, and which ones are entirely incompatible and must therefore be housed in separate building envelopes. The secondary question then becomes how to keep the various units that are housed within the same envelope adequately isolated from one another. The latter question is particularly important if the final product is intended for the human food chain since in most locales very complex rule sets apply to the manufacture of human food and all inputs to its manufacture. These rule sets may come in the form of laws or regulations, may originate at any number of different levels of government (e.g. federal, provincial, municipal) and may be simultaneously enforced in slightly different ways by a number of agencies. The purpose of all of these is to prevent contamination and to assure the quality and safety of the food supply. The aspiring entopreneur will do well to take all applicable rules into account very early during project planning while allocating activities to various units of the proposed facility. This should be part of the PPD exercise.

One key method to house different activities within one envelope is to subdivide it with walls that have very few, if any, penetrations except for those intended for essentials such as utilities, the transport of materials, communications, etc. That way air-borne dust and contaminants as well as most personnel are prevented from moving between areas, making it feasible to house, for example, personnel, air cleaning, feed mixing and tray loading under the same roof as rearing and processing. In this author's opinion it is best and safest to keep all waste treatment and major 
cleaning activities well away from any processing area. Also, because of the often amazing (!) penetration capacity of various types of rodents and stored product insects it is best to maintain physically separate units for shipping and receiving as well as any associated warehousing. Trucks load and unload through very large penetrations in the envelope that must seem like a challenge to any enterprising mouse or rat, the reward being an ample food supply. These units therefore need to be equipped with effective pest management systems. However, considering biological reality, no matter how good a pest control system is, it is never practical to bring the infestation rate down to zero and isolation of high-risk units is an effective way to reduce the incidence of unwanted biological penetration into the processing area even further. Obviously, to what degree the entopreneur needs to worry about this aspect will depend very much on the final product. For instance, if the objective is to produce non-food industrial oil, protein powder and chitin from a biological waste material the concern about contamination and infestation will be a lot less acute than if the product is chicken feed.

Although it will likely not be a primary consideration for most planners of entotechnological projects, the personnel unit is actually quite important not only because it is central to process management and control, but also for reasons of safety, hygiene and employee well-being. Depending on the scale of the production plant, office space for the following divisions will be needed: operations and control; management; sales, marketing and buying; human resources; general accounting, accounts payable, accounts receivable and payroll; janitorial and cleaning services; technical support including for IT; security. As well, space will be needed for bathrooms, showering facilities and laundry, a lunchroom or cafeteria, and even a day-care facility with a recreational area attached. So as to minimise health risks, in Figure 1 the personnel facility is located upwind and well away from the production area, it has its own air supply and a separate parking lot. Although not shown on the diagram, it will also need a separate, secure water supply that is thoroughly protected against contamination through backflow in the system. For intermediate-sized facilities some of the functions mentioned will probably be carried out in combination by a limited number of people. Thus, all financial transactions may be looked after by one person with assistance of an external accounting firm while operations, management, human resources, technical support, and janitorial services could be dealt with by a team of several partners supported by helpers. This would be typical for a family-owned business. For a very small facility most of the tasks will be carried out by one or two people, perhaps working parttime, fulfilling different roles while all activities will be carried out in the same space.

\section{Consideration 4: safety, hygiene and cleaning}

The raising of animals for economic purposes, husbandry, is generally not considered a dangerous undertaking for the humans involved. There are, nevertheless, a number of safety aspects to take into account and these are quite different for the three main approaches to farming: extensive, intensive and 'factory-farming. Especially in the latter case are farm personnel often exposed to a number of industrial-type workplace hazards such as intense noise and odour, dust, ammonia and hydrogen sulphide, drugs and hormones, and even antibiotic-resistant pathogens. Air quality in intensive and factory-farm operations is often quite poor and personnel may run the risk of contracting respiratory diseases (Fox, 1980; Mitloehner and Calvo, 2008). Considering that entotechnology is mainly oriented to the 'factory-farming' method in which insects are reared in confinement at extremely high densities, similar hazard potentials apply to workers in entotechnological environments. A further hazard in this industry is the development of allergic reactions in workers. Bauer and Parnode (1981) have reported on this phenomenon and Kausar (2018) has stated that 'It is quite evident that insects contribute clinically important inhalant allergens to the air in respirable sized particles.' but also that '...the study on allergy caused by insects is limited.' Hence, apart from the mechanical and electrical hazards to which farm workers are generally subject, in this industry there are the inhalation of gases and insect particles as well as extended exposure to insects that can cause health problems. One approach to minimise worker contact and exposure is to automate most of the materials handling but this is not always possible in smaller operations. Sufficient ventilation with clean air is therefore very important for worker safety under all circumstances and in some cases it may be justified to have workers wear face masks and protective clothing to limit their inhalation and exposure. Concomitantly, as shown in Figure 1, in order to safeguard neighbours and passers-by, the exhaust from the rearing facility should be cleaned up to render it safe before it is discharged.

Whereas the consideration of safety is usually oriented to the health and well-being of humans, hygiene and cleaning are meant to secure the farmed species as well as their human farmers. Regardless of what animal is being reared, disease or the potential of disease is always there (Joosten $e t$ $a l ., 2020)$ and a robust system should be in place to minimise its impact when a disease strikes a production facility. Thus, the facility should be designed and constructed in the first place and then also operated so as to make it difficult for a disease organism to propagate. As mentioned above, this can be done by keeping the various production units physically separated as much as possible and to minimise both personnel and material movement between units. Also, in any material or equipment 'backflow' thorough cleaning 
is essential. For instance, in Figure 1 the trays on which the larvae are reared pass through the process in a cycle and thus flow back from the processing unit to the rearing unit, being cleaned in between. Under ideal circumstances those trays should be sterilised (in the 'commercial' sense) and a suitable material to withstand such repeated treatment would be stainless steel. This is, however, a rather expensive option and also not necessarily an optimal material choice for other reasons. Accordingly, during the PPD phase of the project considerable attention should be paid to the selection of materials that will simultaneously meet the various requirements of frequent handling, sterilisation, organism compatibility, etc. Persistent cleaning and 'commercial sterilisation' of other parts of the production facility are also an operating requirement if one is to avoid disease incidence. A well-trained and dedicated janitorial staff is therefore an essential part of the operations teams, no matter what the scale of the facility.

Prevention is the first defence against invasion - this holds for a unitary system such as a single larva but it also holds for large, composite systems such as a production facility which may hold a trillion larvae. Nevertheless, regardless of how well a system is designed and operated, sooner or later a predator or competitor will penetrate all passive defences. This is an unwritten law of nature. There should, therefore, be in place a robust monitoring system that is able to detect problems, coupled to a response system that is ready and primed to deal effectively with those problems. The detection system must rely on continuous and attentive observation of the process and, especially, the behaviour of the organisms. It is mostly deviations from the norm that will be the main response triggers. All operations personnel should be involved in process and organism monitoring and for larger facilities it may be appropriate to have specialised personnel for this, assisted by AI-driven systems. The use of neural networks to detect anomalies in race horse behaviour related to health status was discussed by Suchorski-Tremblay et al. (2001) and Flower et al. (2005) have used kinematic measures to detect hoof gait deviations related to dairy cow pathologies. Similar technologies could be used to generate early warning signals for a larval rearing facility, triggering a request for an entomological pathologist to come identify the problem and recommend action. Basically, the earlier an infection is noted and identified the more effective and the less costly the response will be. In the cattle industry foot-and-mouth disease can spread so rapidly that very fast detection, verification and response activation are essential to prevent major damage. Although it may seem extreme to some, this often involves culling all animals that have even a remote chance of having been infected. The same principles will hold for the factory farming of insects so that, once a disease problem has been identified and its severity established, it may be necessary to thoroughly sterilise an entire section of a rearing facility. To limit the overall damage it is therefore prudent to design, construct and operate a process in a defensive manner. Isolation of the various units from one another and strict hygienic operation lie at the basis of this approach.

\section{Discussion and conclusions}

In the end, the PPD exercise should result in a fairly complete description of the project in which all major design and operational features are dealt with in some detail. Thus, in the first section all the basic questions should be addressed: what is the overall intent and purpose of the project; what organism/feed combination is proposed and how is that justified; which activities will be carried out locally; what is the proposed scale of operation and what will be the impact on the local economic situation; what process type (and reactors) will be employed; what is the control approach; what knowledge is available about this system and what knowledge needs to be developed or expanded; and what will be the main reasoning/mentation approach followed for project development? Evidently, most of the answers will be dependent upon and interactive with similar questions about markets and demand for the product, but most of the details of these subjects are well outside the purview of this paper. If the reasoning and planning approach used is not entirely intuitive (so that it can be traced and inspected by external agents), ideally, the answers to the basic questions will be supported with calculations, simulations, results from experiments, etc. presented in appendices. Market study results and demand forecasts, etc. can also be presented there.

In the second section the facility issues can then be dealt with and the following presented: one or more specific project locations together with their characteristics, advantages and disadvantages; an infrastructure description containing a preliminary facility layout and a discussion of the integration/segregation approach followed; an outline of what functionality will be housed in which envelope and how the envelopes are to be connected; a detailed description of both passive and active safety features for the project that will have to be incorporated in the formal design of the facility and the specifications of the operating procedures (see Figure 1, Kok, 2021a). In the third section of the report a preliminary timeline for the project can be outlined together with items such as possibilities for future expansion, etc. Creating a fairly detailed PPD report as described above is invaluable for the aspiring entopreneur; it both forces them to collect and organise their thoughts into a coherent whole and, at the same time, provides them with 'ammunition' to sell the project to investors. The latter may very well find it an attractive proposition but then want to contribute to its final formulation, stressing the fact that PPD is an iterative procedure. Thus, the project and the report will remain subject to change until an equilibrium is reached between all stakeholders. PPD is, after all, first and foremost an investigation of the possibility 
space and all results thereof can be re-formulated in light of new opportunities and insights. Of course, how formal the interactions between parties and any investment negotiations will be will very much depend on the scale of the project, the relationship between the entopreneur and the investors as well as the overall mentation approach to the project.

So far, very little has been said about the financial aspects of the project and any financial reward that may accrue to investors. This is partially because during the PPD stage of a project the financial aspects are very difficult to gauge. Also, like market study and demand forecasting, etc., the subject is marginal to this paper. The author's approach is, however, that it is normal that investors should want a return on their investment and they will invest only if there is a reasonable chance of financial reward (this is not necessarily true for institutional or government investors who may be motivated more by political than financial reward). Doubtless, the project developer will think about it during PPD but a comprehensive assessment of prospective profitability has to wait until a fairly complete project plan is in place. Hence, this may be done when it is time to present to potential investors (or, for a small project, when the entopreneur needs to convince his banker). In dealing with potential investors the entopreneur should acknowledge that negotiations do not always gravitate towards a mutually satisfactory equilibrium point.

Besides the issues mentioned above, a number of other ones are appearing on the horizon of the entotechnological industry and one might keep these in mind when planning production facilities. The first one is the overall supply of feed. Thus far the main production organisms are BSF, mealworms and crickets. All of these can be used to upgrade and concentrate nutrients from lower grade feeds. But none of these insects are, however, able to synthesise protein, meaning that they are limited to extracting protein from their substrate. They are, therefore, very limited in what they can be grown on by the amount of protein present in their feed. If insects are to become a major item in the human food chain, either directly or indirectly, there will soon be a stress on the feed supply, causing prices to rise, etc. Consequently, the time is ripe to develop the mass culture of insects which can be grown on feeds which are abundantly available at low prices and high in energy, but low in protein content. Such materials are often composed of cellulose and lignin. In order to be useful as feed, they need to be: (1) mechanically degraded; and (2) digested by organisms that are also capable of synthesising protein rather than just extracting it. A number of beetles, some cockroaches and most termites are able to do much of this, aided by bacteria and protozoa living symbiotically in their guts (e.g. see O'Brien and Slaytor, 1982). In some instances the feed can be fortified with low-cost, inorganic nitrates as a nitrogen source for protein synthesis while in some others the microorganisms, and by extension the insect, are able to synthesise protein de novo from atmospheric nitrogen (Täyasu et al., 1994). The advantage of cheap, cellulosic feeds is that, although low in nutritional content, they are often not heavily contaminated and therefore not so difficult to have approved for entry into the human food chain.

'Nature abhors a vacuum' is a truism that certainly holds in biology! Thus, although an organism such as BSF is presently quite resistant to infection and disease (Joosten et al., 2020), once it is reared in great quantities at high concentrations it is more than likely to prove an irresistible temptation to the forces of evolution, adaptation and procreation as well as fate. It is, therefore, to be expected that various parasitic and disease organisms will develop and, sooner or later, make a strong appearance in production facilities. As discussed, the impact of this can be partly offset by preventive design tactics combined with safe, hygienic operating procedures and continuous monitoring. The latter functionality should be able to call upon an incidence response team that includes an entomological pathologist. The point here is that the entotechnological industry should be stimulating and supporting the training of veterinary personnel specialised in production-related entomological issues. As well, it should be supporting research into pest and disease control methods. While it is a good strategy to both prevent and combat disease, it is also wise to develop approaches to avoid problems. A primary method to do that is 'to run faster than the opponent'. This relies on the ongoing development of new strains that are resistant to upcoming problems. Thus, by the time a pest or disease is on the verge of becoming a significant problem, production is switched over to a strain that is resistant to that specific organism. This obviously requires a serious commitment to strain development which should also be supported by the industry as a whole for all species of commercial interest. Kok (2017) has also discussed this issue, pointing out that the inclusion of new genetic material and the development of new strains should always happen in isolation, preferably in an entirely separate unit, well away from production.

A third issue that is now appearing on the entotechnological horizon concerns animal welfare. For a not-so-clear reason invertebrate creatures are generally regarded as not being able to 'suffer' so that animal welfare legislation is not applicable to them, the exception in this regard in many locales being the cephalopods. This situation may, however, change as attitudes about stress and the welfare of farmed insects mutate, as they have about traditionally farmed animals. The same arguments used earlier by mammalian and avian welfare proponents (e.g. Fox, 1980) to encourage people to change their attitudes may soon also be used by arthropodal welfare advocates. Indeed, this issue is already being actively discussed in the literature (e.g. Gjerris et al., 2016). From a process and facility design perspective it will therefore be discreet to not draw attention to this 
aspect of entotechnology as well as to assure that insects are reared under conditions that will not be easy to interpret as causing them 'suffering'. Avoidance of problems of this type is probably the best approach. The industry should aim for 'happy larvae that are slaughtered as humanely as possible'.

\section{Conflict of interest}

The author declares no conflict of interest.

\section{References}

Bauer, M. and Parnode, R., 1981. Health hazard evaluation report HETA 81-0121-1421 - CDC - Insect rearing facilities. Agricultural Research Service, USDA, Washington, DC, USA. Available at: https://www.cdc.gov/niosh/hhe/reports/pdfs/81-121-1421.pdf

Eilenberg, J., Vlak, J.M., Nielsen-Leroux, C., Cappellozza, S. and Jensen, A.B., 2015. Disease in insects produced for food and feed. Journal of Insects as Food and Feed 1: 87-102. https://doi.org/10.3920/ JIFF2014.0022

Flower, F.C., Sanderson, D.J. and Weary, D.M., 2005. Hoof Pathologies Influence Kinematic Measures of Dairy Cow Gait. Journal of Dairy Science 88: 3166-3173. https://doi.org/10.3168/jds.S00220302(05)73000-9

Fox, M.W., 1980. Factory farming. Miscellaneous studies and reports. Available at: https://www.wellbeingintlstudiesrepository.org/ sturep/2

Gjerris, M., Gamborg, C. and Röcklinsberg, H., 2016. Ethical aspects of insect production for food and feed. Journal of Insects as Food and Feed 2: 101-110. https://doi.org/10.3920/JIFF2015.0097

Jones, P.J., Niemi, J., Christensen, J.-P., Tranter, R.B. and Bennett, R.M., 2018. A review of the financial impact of production diseases in poultry production systems. Animal Production Science 59: 15851597. https://doi.org/10.1071/AN18281

Joosten, L., Lecocq, A., Jensen, A.B., Haenen, O., Schmitt, E. and Eilenberg, J., 2020. Review of insect pathogen risks for the black soldier fly (Hermetia illucens) and guidelines for reliable production. Entomologia Experimentalis et Applicata 168: 432-447. https://doi. org/10.1111/eea.12916

Kausar, M.A., 2018. A review of respiratory allergy caused by insects. Bioinformation 14: 540-553. https://doi.org/10.6026/97320630014540
Kok, R., 2017. Insect production and facility design. In: Van Huis, A. and Tomberlin, J.K. (eds.) Insects as food and feed: from production to consumption. Wageningen Academic Publishers, Wageningen, the Netherlands, pp. 142-172.

Kok, R., 2021a. Preliminary project design for insect production: part 1 - overall mass and energy/heat balances. Journal of Insects as Food and Feed 7: 499-509. https://doi.org/10.3920/JIFF2020.0055 Kok, R., 2021b. Preliminary project design for insect production: part 2 - organism kinetics, system dynamics and the role of modelling \& simulation. Journal of Insects as Food and Feed 7: 511-523. https:// doi.org/10.3920/JIFF2020.0146

Kok, R., 2021c. Preliminary project design for insect production: part 3 - sub-process types and reactors. Journal of Insects as Food and Feed 7: 525-539. https://doi.org/10.3920/JIFF2020.0145

Liu, C., Masri, J., Perez, V., Maya, C. and Zhao, J., 2020. Growth performance and nutrient composition of mealworms (Tenebrio molitor) fed on fresh plant materials-supplemented diets. Foods 9: 151. https://doi.org/10.3390/foods9020151

Mitloehner, F.M. and Calvo, M.S., 2008. Worker health and safety in concentrated animal feeding operations. Journal of Agricultural Safety and Health 14: 163-187. https://doi.org/10.13031/2013.24349

O'Brien, R.W. and Slaytor, M., 1982. Role of microorganisms in the metabolism of termites. Australian Journal of Biological Sciences 35: 239-262. https://doi.org/10.1071/BI9820239

Pitts, N. and Whitnall, T., 2019. Impact of African swine fever on global markets. Agricultural Commodities 9: 52-54.

Ritchie, H. and Roser, M., 2017. Meat and dairy production. Available at: https://ourworldindata.org/meat-production

Ritchie, H. and Roser, M., 2019. Seafood production. Available at: https://ourworldindata.org/seafood-production

Suchorski-Tremblay, A.M., Kok, R. and Thomason, J.J., 2001. Modelling horse hoof cracking with artificial neural networks. Canadian Biosystems Engineering 43: 7.15-7.22.

Täyasu, I., Sugimoto, A., Wada, E. and Abe, T., 1994. Xylophagous termites depending on atmospheric nitrogen. Naturwissenschaften 81: 229-231. https://doi.org/10.1007/BF01138550

Ubeda, Y., Lopez-Jimenez, P.A., Nicolas, J. and Calvet, S., 2013. Strategies to control odours in livestock facilities: a critical review. Spanish Journal of Agricultural Research 11: 1004-1015. 
